\title{
Studies of In Vitro Primaquine Hemolysis: Substrate Requirement for Erythrocyte Membrane Damage*
}

\author{
James N. George, $\dagger$ Richard L. O’Brien, Simeon Pollack, and William H. \\ Crosby with the tech nical assistance of Donna J. Wicker \\ (From the Division of Medicine, Walter Reed Army Institute of Research, Washington, D. C.)
}

The hemolytic toxicity of primaquine has been recognized since its introduction as an antimalarial drug $(2,3)$. Both in vivo and in vitro primaquine hemolysis has been extensively characterized, but the actual mechanisms of red cell destruction are still unknown $(4,5)$. These two processes differ from one another in that much greater concentrations of primaquine are required for in vitro hemolysis (6). During this study of the mechanisms of primaquine hemolysis, we made the apparently paradoxical observation that red cells deficient in glucose 6-phosphate dehydrogenase (G-6-PD), although more sensitive than normal cells to primaquine hemolysis in vivo, are less sensitive to primaquine-induced changes in an in vitro system containing substrate. This led us to examine the relationship between erythrocyte metabolism and in vitro primaquine damage.

The metabolic basis of oxidative hemolysis has been studied extensively in vitro $(5,7)$. The theme of previous studies has been the requirement of intact metabolic pathways for protection against oxidative damage. This protection was related to glutathione reduction and maintenance of peroxidase activity (4), methemoglobin reduction (8), ATP production for active transport (9), and TPNH production for cell membrane repair (10). The decreased ability of G-6-PD deficient erythrocytes to carry out these active processes has been used to explain their susceptibility to oxidative hemolysis. The present finding of a metabolic requirement for primaquine-induced red cell membrane damage is in contrast to these previous re-

* Submitted for publication September 28, 1965; accepted May 5, 1966.

Parts of this paper have previously appeared in abstract form (1). It is contribution no. 43 from the Army Research Program on Malaria.

$\dagger$ Address requests for reprints to Capt. James $\mathrm{N}$. George, MC, Dept. of Hematology, Walter Reed Army Medical Center, Washington, D. C. 20012. sults and again demonstrates a fundamental difference between in vitro and in vivo systems. In addition to these metabolic relationships, we were able to demonstrate that the in vitro primaquine effect is probably due to a structural change in the erythrocyte membrane.

\section{Methods}

Blood from normal adult males was collected in heparin. Erythrocytes were separated from plasma by centrifugation and washed three times in $0.9 \%$ sodium chloride (referred to as saline). G-6-PD was determined by measuring the reduction of TPN to TPNH in a Beckman DB spectrophotometer at $340 \mathrm{~m} \mu .{ }^{1}$ The values obtained for normal individuals whose red cells were used in this study were $1.693 \pm 0.313$ (SD) $\mathrm{U}^{2}$ per $\mathrm{ml}$ of red cells. Erythrocytes from the five Negro male G-6-PD deficient individuals had enzyme activities of $0.166 \pm$ $0.032 \mathrm{U}$ per $\mathrm{ml}$ of red cells. All experiments used normal red cells unless otherwise indicated.

Incubations were in siliconized 25-ml Erlenmeyer flasks in air in a shaking water bath at $37^{\circ} \mathrm{C}$. One $\mathrm{ml}$ of washed red blood cells was added to $2 \mathrm{ml}$ of a saline solution containing the appropriate constituents. For experiments in which red cells were depleted of substrate, the cells were prepared by preincubation at $37^{\circ} \mathrm{C}$ for 2 hours before the addition of the hemolytic drug. All incubations were for 2 hours unless otherwise stated.

Primaquine diphosphate, pamaquine citrate, isopentaquine oxalate, ${ }^{3}$ hydroquinone, and menadione sodium bisulfite were dissolved in saline before incubation, and the $\mathrm{pH}$ was adjusted to 7.4 with sodium hydroxide. Crystalline acetylphenylhydrazine and $\beta$-naphthol were added directly to the incubation mixture. Neither of these drugs altered the $\mathrm{pH}$ of the red cell suspension. The $\mathrm{pH}$ of the reaction mixture remained constant during incubation unless glucose or other metabolized hexoses were added. Then a small decrease of $\mathrm{pH}$ (less than $0.2 \mathrm{U}$ )

\footnotetext{
1 Materials obtained in kit form from Calbiochem, Los Angeles, Calif.

2 Enzyme units defined as micromoles of substrate reduced (or oxidized) per minute per unit of material (11).

3 Pamaquine and isopentaquine generously supplied by Dr. Robin D. Powell, Army Medical Research Unit of the Dept. of Medicine, University of Chicago, Chicago, III.
} 
occurred. This was shown to have only a slight effect on osmotic fragility by preliminary experiments in which the $\mathrm{pH}$ of the incubation mixture was decreased $0.2 \mathrm{U}$ with $\mathrm{HCl}$ before incubation. Increase in hemolysis was less than $5.4 \%$ in $0.85 \% \mathrm{NaCl}$ in four experiments.

Hemoglobin determinations by the cyanmethemoglobin method of Crosby, Munn, and Furth (12) were carried out on the whole blood sample and the supernatant medium after incubation. Hematocrits were determined by the microhematocrit method. Per cent hemolysis was calculated as :

$\%$ hemolysis $=\left[O D_{\text {supernatant }}(1-\mathrm{Hct}) /\right.$ OD whole sample $X$ dilution factor $] \times 100$.

The dilution factor varied from 1 to 10 , depending upon the amount of supernatant material used in the hemoglobin determination.

Potassium concentrations were determined by flame photometry with an internal lithium standard. The loss of potassium from the red cells to the supernatant fluid was calculated as :

$$
\% \text { potassium loss }=\left[\mathrm{K}_{\mathrm{s}}(1-\mathrm{Hct}) / \mathrm{K}_{\mathrm{RBC}} \times 0.33\right] \times 100 \text {. }
$$

$\mathrm{K}_{\mathrm{s}}$ is the potassium concentration of the supernatant fluid after incubation, and Hct refers to the microhematocrit of the red cell suspension after incubation. $\mathrm{K}_{\mathbf{R B C}}$ is the potassium concentration of the washed, packed red cells before incubation, and 0.33 refers to the initial concentration of these packed cells in the incubation system. No correction for trapped fluid, which was potassium free, was necessary in calculating $\mathrm{K}_{\mathbf{R B C}}$, since the total volume of packed cells added to the suspension was the volume in which $\mathrm{K}_{\mathbf{R B C}}$ was contained. It should be recognized that this equation oversimplifies the expression of the loss of the red cell's ability to actively maintain its potassium concentration. This was apparent in other experiments in our primaquine incubation system when equilibrium between intracellular and extracellular potassium was attained, and yet a significant proportion of the potassium remained within the still intact cells.

Osmotic fragility was determined after incubation by transferring $0.02 \mathrm{ml}$ of the incubation mixture into $5 \mathrm{ml}$ of buffered sodium chloride solutions of varying concentrations and distilled water as described by Parpart and as-

TABLE I

Effect of substrate addition and depletion on potassium loss and hemolysis produced by primaquine*

\begin{tabular}{|c|c|c|c|}
\hline \multicolumn{2}{|c|}{$\%$ Hemolysis } & \multicolumn{2}{|c|}{$\%$ Potassium loss } \\
\hline Addition & Depletion & Addition & Depletion \\
\hline $\begin{array}{r}3.82 \pm 1.58 \\
p\end{array}$ & $\begin{array}{l}1.21 \pm 0.20 \\
0.001\end{array}$ & $\begin{array}{r}28.04 \pm 4.41 \\
p\end{array}$ & $\begin{array}{l}25.16 \pm 3.88 \\
0.050\end{array}$ \\
\hline
\end{tabular}

* Incubation systems included: addition $-4 \mathrm{mM}$ primaquine and $10 \mathrm{mM}$ glucose in saline, or depletion $-4 \mathrm{mM}$ primaquine added to a saline suspension of red cells after preincubation for 2 hours at $37^{\circ} \mathrm{C}$. Figures represent the mean $\pm 1 \mathrm{SD}$ of four separate experiments, including 15 observations on the red cells of 14 normal males.

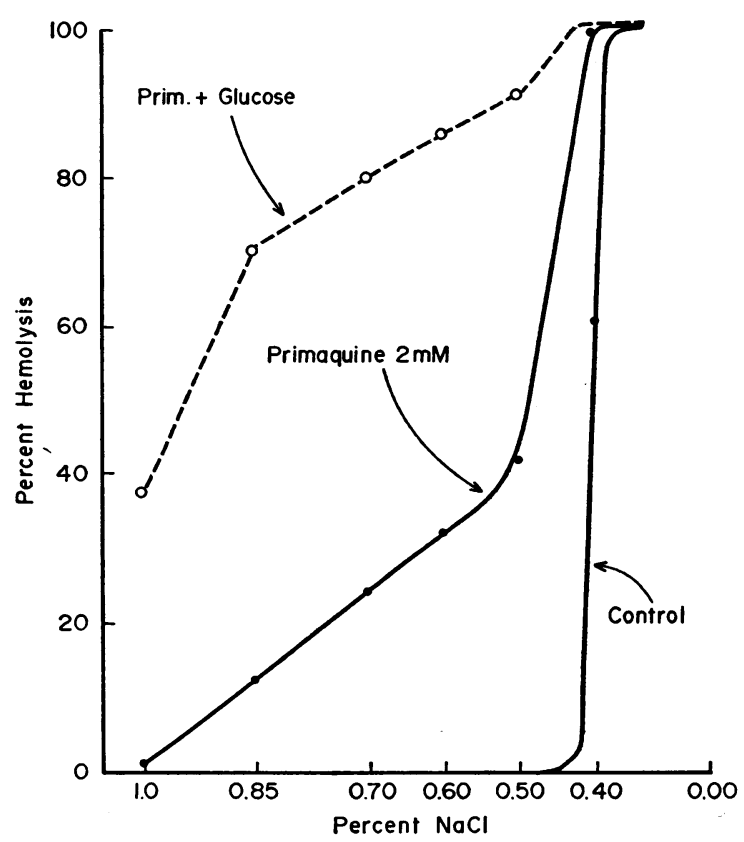

Fig. 1. The efFect of glucose on OSMOtic Fragility PRODUCEd IN NORMAL RED CELls bY PRIMAQUiNe. Samples were incubated for 2 hours without primaquine (control), with $2 \mathrm{mM}$ primaquine, and with $2 \mathrm{mM}$ primaquine plus $10 \mathrm{mM}$ glucose. The figures represent the mean values of nine and seven experiments.

sociates (13). These samples were allowed to stand at room temperature for 1 hour, were centrifuged, and optical density at $540 \mathrm{~m} \mu$ was determined in a Coleman Junior spectrophotometer. The sample in distilled water was designated as $100 \%$ hemolysis. Acetylphenylhydrazine and to a lesser extent menadione sodium bisulfite caused partial hemoglobin precipitation. Therefore, the osmotic fragility curves for these drugs are not representative of the entire population of red blood cells. Primaquine, pamaquine, isopentaquine, hydroquinone, and $\beta$-naphthol presented no such problems.

Primaquine concentrations were estimated by absorbancy at $420 \mathrm{~m} \mu$ on metaphosphoric acid extracts of the incubation mixture or supernatant.

\section{Results}

Effect of substrate on potassium loss, hemolysis, and osmotic fragility. Increasing concentrations of primaquine caused the loss of red cell potassium before the onset of hemolysis. At sublytic concentrations, primaquine produced a pattern of red cell osmotic fragility characterized by a small population of osmotically fragile cells. The primaquine concentration required for these changes was similar to that previously reported $(6,14)$. The addition of glucose or the depletion of en- 


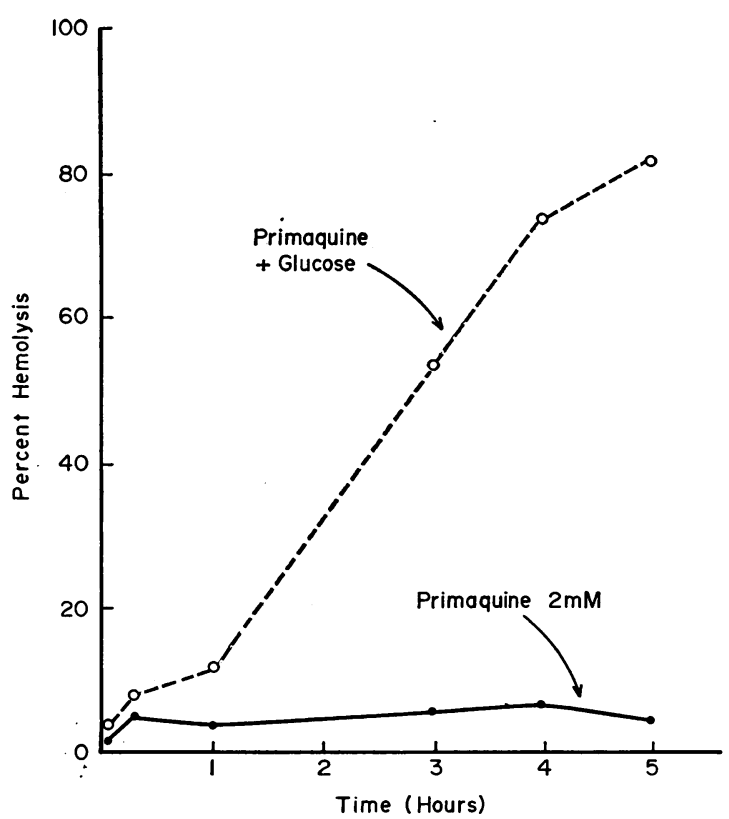

Fig. 2. The efFect of GLUCOSE ON OSMOTIC FRAGIlity PRODUCED IN NORMAL RED CELLS BY PRIMAQUINE. Samples were incubated with $2 \mathrm{mM}$ primaquine with or without added $10 \mathrm{mM}$ glucose, and hemolysis in $0.85 \% \mathrm{NaCl}$ was tested at timed intervals. This figure is representative of three experiments.

dogenous substrates had no effect on potassium loss, but hemolysis was significantly increased in the presence of substrate (Table I). Adding glucose also caused a marked decrease in resistance to osmotic lysis (Figure 1). The relationship of red cell size and shape to primaquine-induced osmotic fragility was studied after incubation with and without glucose for varying times. Primaquine alone caused a small decrease in osmotic resistance (Figure 2). Table II shows that there was no increase in cell size as incubation proceeded and that the shape of red cells incubated with primaquine alone was unchanged after 5 hours. The presence of glucose in the hemolytic system caused the appearance of marked spherocytosis beginning between 1 and 3 hours, when the osmotic fragility became greater than with primaquine alone.

To define further the effect of glucose in supporting primaquine hemolysis, various other sugars were tested for their effect on primaquine-induced osmotic fragility (Table III). Pentoses are actively transported into the red cell by the same mechanism as glucose (15), but they are not significantly metabolized (16). D-Ribose, D-xylose, and L-arabinose had no effect on $2 \mathrm{mM}$ primaquine-induced osmotic fragility. The effect of other metabolized hexoses, D-fructose, D-mannose, and $\mathrm{D}$-galactose was similar to glucose in enhancing primaquine-induced osmotic fragility. L-Sorbose, which is similarly transported across the red cell membrane (15) but not metabolized (17) had no effect.

2-Deoxyglucose is transported into human red cells as readily as glucose, and then it competitively inhibits glucose metabolism (18). When this drug was added to the primaquine incubation system, the appearance of osmotic fragility was diminished (Figure 3). Depletion of endogenous substrates almost completely prevented primaquine from acting to cause increased osmotic fragility.

The pentose moiety of purine nucleosides is split off and phosphorylated at the red cell membrane and subsequently metabolized (19). Adenosine and guanosine increased primaquineinduced osmotic fragility as much as glucose (Fig-

TABLE II

Erythrocyte volume: shape changes with primaquine*

\begin{tabular}{|c|c|c|c|c|}
\hline \multirow[b]{2}{*}{ Time } & \multicolumn{2}{|c|}{ Primaquine } & \multicolumn{2}{|c|}{ Primaquine + glucose } \\
\hline & $\mathrm{MCHC}$ & RBC shape & $\mathrm{MCHC}$ & RBC shape \\
\hline \multicolumn{5}{|l|}{ hours } \\
\hline 0 & 31.7 & Biconcave discs & 31.7 & Biconcave discs \\
\hline 0.25 & 32.3 & Biconcave discs & 32.1 & Biconcave discs \\
\hline 1.0 & 31.3 & Biconcave discs & 31.8 & Biconcave discs \\
\hline 3.0 & 31.6 & Biconcave discs & 31.5 & Beginning spherocytosis \\
\hline 5.0 & 33.4 & Biconcave discs & 31.6 & Marked spherocytosis \\
\hline
\end{tabular}

* Incubation was at $37^{\circ} \mathrm{C}$ with $2 \mathrm{mM}$ primaquine alone or with $10 \mathrm{mM}$ glucose. Erythrocyte volume was judged by dividing hemoglobin concentration by hematocrit to determine mean corpuscular hemoglobin concentration (MCHC). Erythrocyte shape was determined by examination of fresh, unstained cells under a coverslip. Recorded values for MCHC represent the mean of two experiments on different days. Shape changes were the same on each day. RBC $=$ red blood cells. 
TABLE III

Effect of various sugars and products of metabolism on osmotic fragility caused by primaquine*

\begin{tabular}{ccc}
\hline \multicolumn{2}{c}{ Sample } & \% Hemolysis \\
\hline Primaquine alone & $(13)$ & 12.4 \\
+ D-Fructose & $(2)$ & 58.6 \\
+ D-Galactose & $(5)$ & 58.9 \\
+ D-Glucose & $(10)$ & 62.6 \\
+ D-Mannose & $(4)$ & 47.1 \\
+ L-Sorbose & $(2)$ & 7.9 \\
+ L-Arabinose & $(2)$ & 13.5 \\
+ D-Ribose & $(2)$ & 10.8 \\
+ D-Xylose & $(3)$ & 14.5 \\
& $(2)$ & 10.2 \\
+ Na lactate & + Na pyruvate & $(2)$
\end{tabular}

* Incubation was at $37^{\circ} \mathrm{C}$ for 2 hours with $2 \mathrm{mM}$ primaquine alone or with the addition of a sugar, lactate, or pyruvate in a $10 \mathrm{mM}$ concentration. After incubation, osmotic hemolysis in $0.85 \% \mathrm{NaCl}$ was determined. Figures represent the mean value of the number of observations given in parentheses.

ure 4). Adenine ( $2 \mathrm{mM}$ ) and 2 and $20 \mathrm{mM} \mathrm{ATP}$ had no effect. Deoxyribose from deoxyadenosine is phosphorylated as well as ribose by red cell membrane nucleoside phosphorylase but subse-

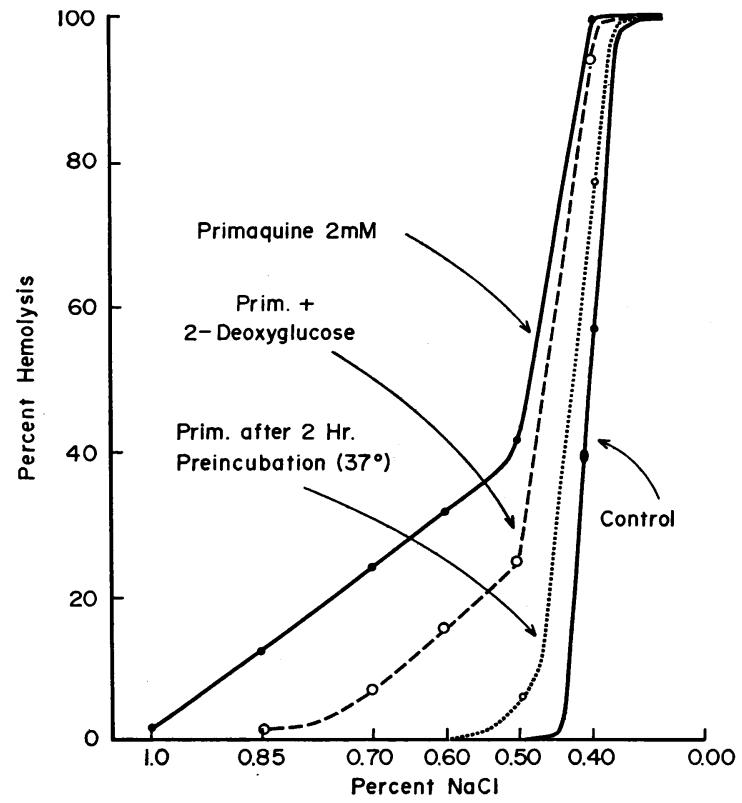

Fig. 3. The EFFECt of 2-DEOXYglucose AND SUbStrate DEPLETION ON OSMOTIC FRAGILITY PRODUCED IN NORMAL RED CELLS BY PRIMAQUINE. Samples were incubated for 2 hours without primaquine (control), with $2 \mathrm{mM}$ primaquine, with primaquine plus $10 \mathrm{mM}$ 2-deoxyglucose, and with primaquine added after preincubation of the red cells. The figures represent the mean values of two to nine experiments. quently is less completely metabolized (20). When added to primaquine incubation systems, deoxyadenosine consistently had an intermediate effect in stimulating osmotic fragility.

The ability of glucose, galactose, and adenosine to support primaquine-induced osmotic fragility was related to substrate concentration (Figure 5). The minimal effective concentration of both glucose and adenosine was $5 \times 10^{-4}$ mole per L. As described above, galactose was as effective as glucose in $10^{-2} \mathrm{M}$ concentrations. However, at concentrations of less than $10^{-2}$ mole per L, galactose was much less effective than glucose.

A further indication of the metabolic nature of the glucose effect was its temperature dependence. Figure 6 represents the increase in primaquineinduced osmotic fragility caused by the presence of glucose at $37^{\circ}, 26^{\circ}$, and $4^{\circ} \mathrm{C}$. Diminishing incubation temperature to $26^{\circ}$ almost abolished the glucose effect. At $4^{\circ}$ glucose was only minimally effective in stimulating primaquine action. The relation of incubation temperature to osmotic fragility itself was less simple. Primaquine was less

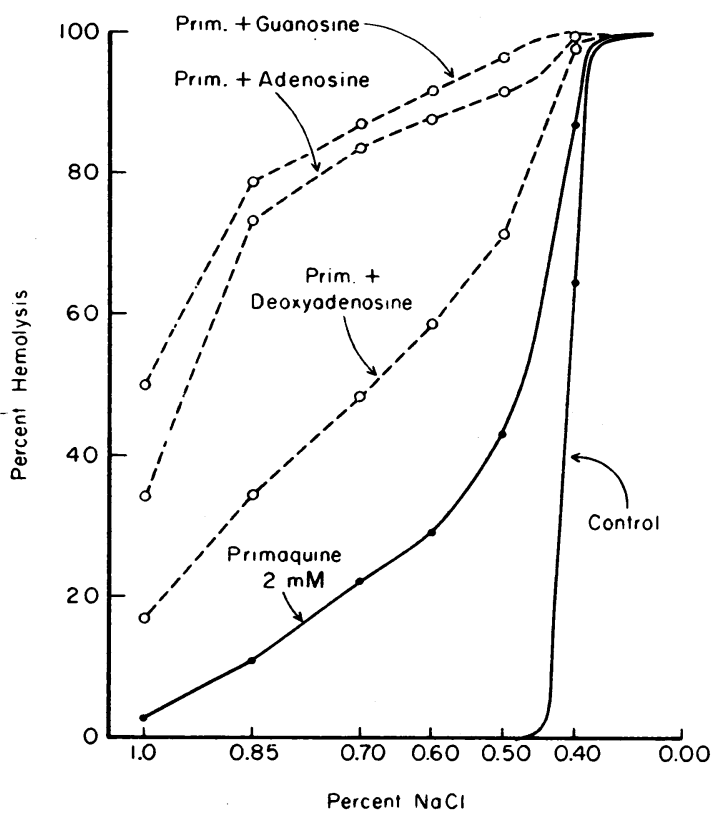

Fig. 4. The efFect OF PURINe NUCleosides ON OSMOTIC FRAGILITY PRODUCED IN NORMAL RED CELLS BY PRIMAQUine. Samples were incubated for 2 hours without primaquine (control), with $2 \mathrm{mM}$ primaquine, and with $2 \mathrm{mM}$ primaquine plus various purine nucleosides ( $2 \mathrm{mM}$ concentrations). The figures represent the mean values of three experiments. 


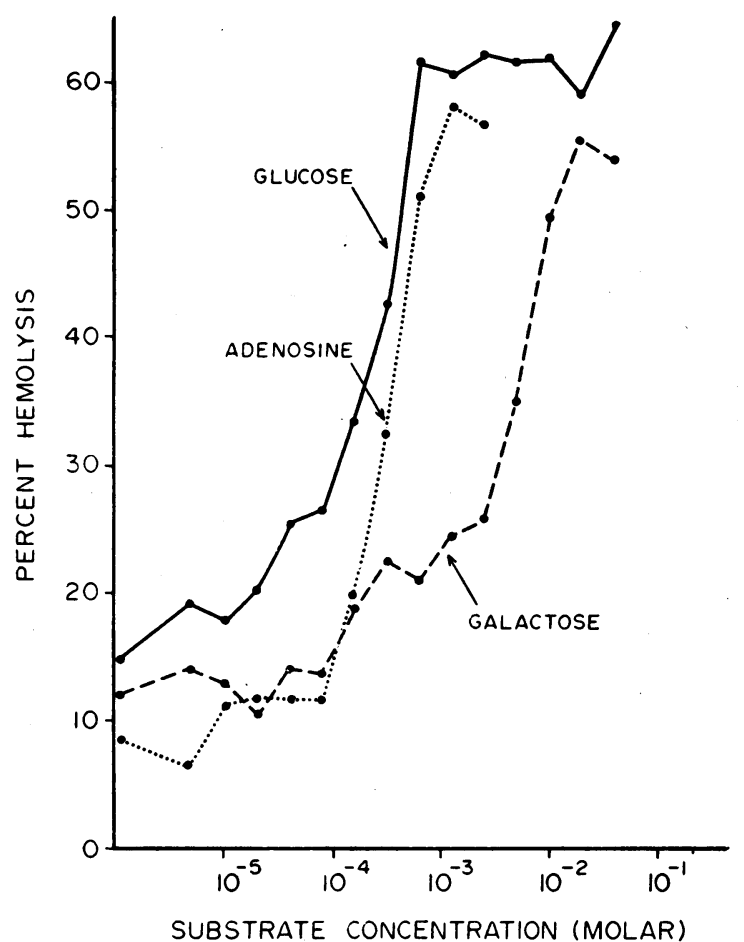

Fig. 5. THE EFFeCt OF SUbSTRATE CONCENTRATION ON THE INCREASE IN PRIMAQUINE-INDUCED OSMOTIC FRAGILITY IN NORMAL RED CELLS. Hemolysis was tested in $0.85 \%$ $\mathrm{NaCl}$ after a 2-hour incubation with $2 \mathrm{mM}$ primaquine alone and with various concentrations of glucose, adenosine, and galactose. The figures are representative of one to four experiments.

effective at $26^{\circ}$, but at $4^{\circ}$ it produced even greater osmotic fragility than at $37^{\circ}$. This phenomenon is currently being studied.

Effect of products of metabolism. The end product of red cell glucose metabolism, lactate itself, could be the stimulatory factor of primaquine action, or an intermediary metabolite accumulated behind a metabolic block may be responsible. Oxidative hemolytic compounds have been shown to decrease lactate production, suggesting a metabolic block (21). For example, acetylphenylhydrazine oxidizes DPNH in vitro and causes the accumulation of pyruvic acid in hemolysates (22). Neither sodium lactate nor sodium pyruvate had any effect on the osmotic fragility of red cells incubated with primaquine (Table III).

G-6-PD deficient red cells. G-6-PD deficient red cells demonstrate the same in vitro potassium loss and hemolysis as normal cells when incubated with primaquine (23). Primaquine also induces the same degree of osmotic fragility in normal and
G-6-PD deficient red cells. The presence of glucose caused an increase in primaquine-induced osmotic fragility of the G-6-PD deficient cells, but the increase was significantly less than that caused in normal cells (Figure 7). Purine nucleosides were also less effective in stimulating primaquine action on G-6-PD deficient red cells than in normal cells.

Other hemolytic agents. Two other 8-aminoquinoline antimalarial drugs, pamaquine and isopentaquine, were studied. In $2 \mathrm{mM}$ concentrations both produced a pattern of erythrocyte osmotic fragility similar to that produced by primaquine. The addition of $10 \mathrm{mM}$ glucose to these systems also caused a marked increase in the osmotic fragility of the red cells. Acetylphenylhydrazine, $\beta$-naphthol, hydroquinone, and menadione sodium bisulfite were also found to increase the osmotic fragility of erythrocytes. With the exception of

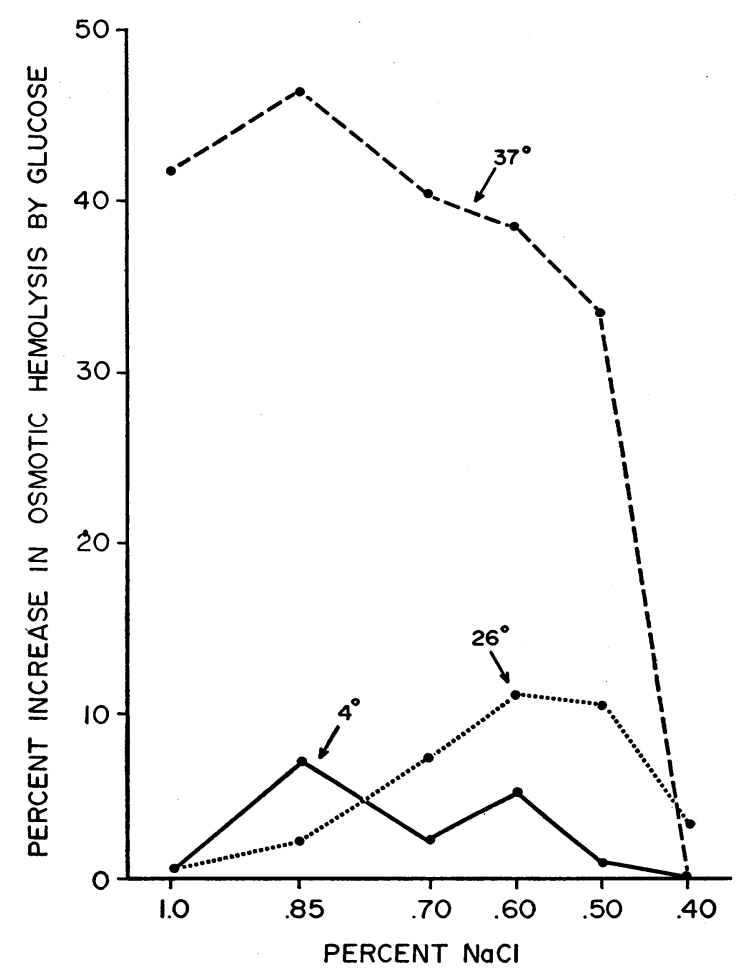

Fig. 6. The efFect of incubation temperature on THE INCREASE IN PRIMAQUINE-INDUCED OSMOTIC FRAGILITY PRODUCED IN NORMAL RED CELLS BY GLUCOSE. Samples were incubated with $2 \mathrm{mM}$ primaquine with or without added $10 \mathrm{mM}$ glucose at $37^{\circ}, 26^{\circ}$, and $4^{\circ}$. The increase in per cent hemolysis produced by glucose at various $\mathrm{NaCl}$ concentrations is charted. The figures are representative of two experiments. 


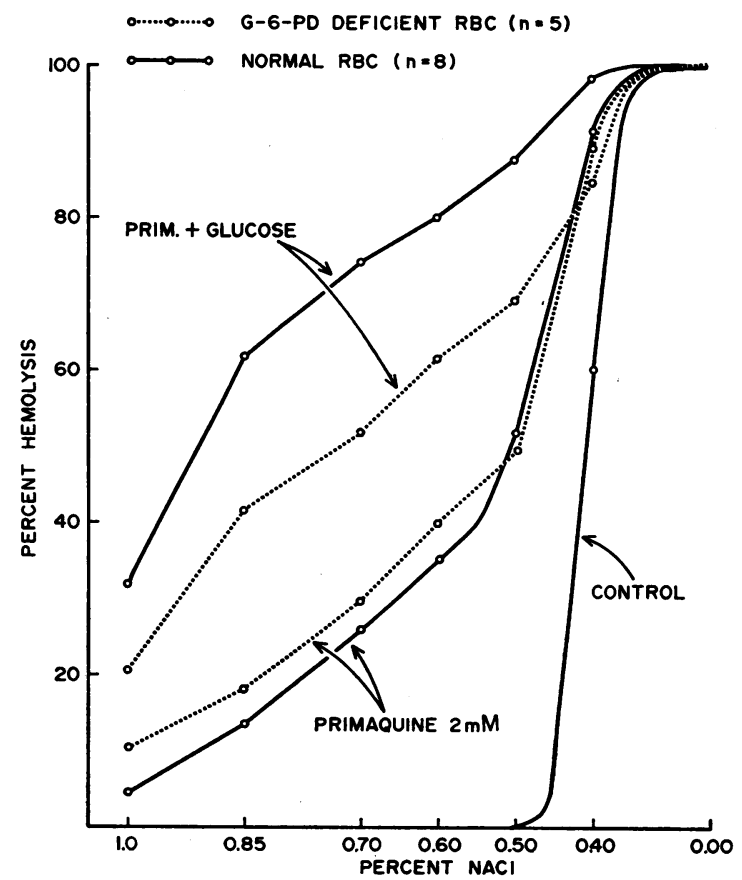

Fig. 7. THE EFFECT OF GLUCOSE ON OSMOTIC FRAGILITY PRODUCED BY PRIMAQUINE IN NORMAL AND G-6-PD DEFICIENT RED CELLS. Both normal and glucose 6-phosphate dehydrogenase (G-6-PD) deficient red cells (RBC) were incubated for 2 hours without primaquine (control) and with $2 \mathrm{mM}$ primaquine with or without added 10 $\mathrm{mM}$ glucose. The figures represent the mean values of five G-6-PD deficient and eight normal subjects. Control curves for normal and G-6-PD deficient cells were the same.

$\beta$-naphthol, far greater concentrations of these agents had to be used to attain an increase in osmotic fragility similar to that caused by $2 \mathrm{mM}$ primaquine in 2 hours. This agrees with Harley and Mauer (24), who found that $\beta$-naphthol and primaquine caused increased osmotic fragility out of proportion to other oxidative damage when compared with acetylphenylhydrazine. They also reported that $\beta$-naphthol- and primaquine-induced osmotic fragility was enhanced by glucose. In the present study only the primaquine effect was stimulated by glucose. The addition of glucose had no effect on the action of acetylphenylhydrazine. With $\beta$-naphthol, hydroquinone, and menadione sodium bisulfite hemolysis was visibly less, and osmotic fragility decreased in the presence of glucose (Figure 8). Depletion of substrate before the addition of the hemolytic agent slightly enhanced the osmotic fragility caused by all four of these other oxidative agents. Therefore, in con-

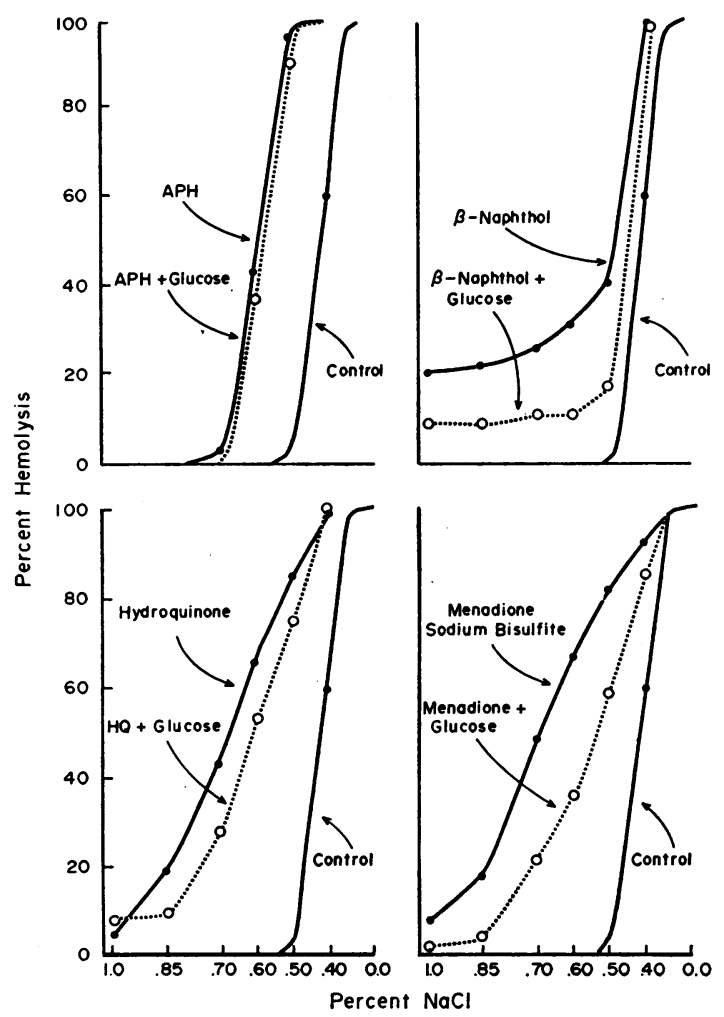

Fig. 8. THE EFFECT OF GLUCOSE ON OSMOTIC FRAGILITY PRODUCED IN NORMAL RED CELLS BY OTHER OXIDATIVE HEMOLYTIC AGENTS. Samples were incubated for 2 hours with saline alone (control) and with $100 \mathrm{mM}$ acetylphenylhydrazine (APH), $4 \mathrm{mM} \quad \beta$-naphthol, $20 \mathrm{mM}$ hydroquinone, and $35 \mathrm{mM}$ menadione sodium bisulfite, both with and without added $10 \mathrm{mM}$ glucose. The figures are representative of one or two experiments.

trast to primaquine, metabolic activity acted to protect the red cell against the action of these drugs.

Primaquine uptake and binding by red cells. Primaquine uptake by red cells was studied to de-

TABLE IV

Effect of substrate on red cell uptake of primaquine*

\begin{tabular}{cc}
\hline \hline Glucose added & Primaquine uptake \\
\hline 0 & $3.89 \pm 0.52$ \\
+ & $4.12 \pm 0.76$
\end{tabular}

* Primaquine uptake was measured in our standard $33 \%$ red cell suspension immediately after mixing red cells with the drug. Primaquine $(2 \mathrm{mM})$ was added either alone or with $10 \mathrm{mM}$ glucose. Figures represent the mean values $( \pm 1 \mathrm{SD}$ ) of the ratio of the primaquine concentration of the red cells to the primaquine concentration of the supernate. Data obtained from red cells of nine normal individuals on 4 separate days. 
termine whether or not substrate served as a source of energy for primaquine transport or binding to its site of action. Primaquine was taken up by red cells in less time than it takes to mix and centrifuge the sample. During 2 hours of incubation at $37^{\circ}$ there was no further cellular accumulation of primaquine. Red cell uptake of primaquine was independent of substrate concentration (Table IV).

After primaquine uptake had been determined, the red blood cells were washed once in 20 vol of saline, which removed more than $90 \%$ of the primaquine. This occurred regardless of the presence or depletion of substrate. The concentration of primaquine remaining in the cells after washing one to six times was the same but below the level of accuracy of this method. Therefore, whether a smaller but significant amount of primaquine is irreversibly bound to the red cells was not determined.

\section{Discussion}

Substrate stimulation of primaquine hemolysis provides further evidence of damage to the erythrocyte membrane, but of a type different from that responsible for prelytic potassium loss. The addition of glucose had no effect on potassium loss but caused a significant increase in hemolysis. Therefore, membrane damage indicated by cation permeability was unchanged, but the ability of the red cell to resist subsequent lysis was diminished. This was more clearly revealed by studies of osmotic fragility. Osmotic hemolysis is the result of progressive swelling of the red cell until lysis occurs at the critical hemolytic volume. Increased osmotic fragility may occur by two processes: the red cell may become more permeable to cations and therefore reach its critical hemolytic volume sooner, or the critical volume itself may be decreased allowing less swelling before hemolysis (25). Increased cation permeability as a cause for the enhancement of primaquine-induced osmotic fragility by glucose seemed unlikely, since there was no increase of potassium loss during incubation in the presence of glucose. The alternative explanation of diminished critical volume was confirmed by demonstrating spherocytosis without a cell volume change caused by primaquine with glucose. Primaquine alone produced no spherocytosis under these conditions. Such a shape change of the red cell without an accompanying volume change indicates direct membrane damage by a diminished surface area and therefore a decreased critical hemolytic volume.

Explanations other than a metabolic effect were at first considered for the mechanism of glucose stimulation of primaquine action. Initially, it was considered that glucose may act only to increase the intracellular osmotic pressure after being actively transported into the cell. This was dismissed by the demonstration that only actively metabolized compounds supported increased primaquine hemolysis. Actively transported but nonmetabolized substances had no effect. Another early consideration was that the monosaccharide transport system itself may be involved in the stimulation of primaquine hemolysis. Erythrocyte membrane sulfhydryl groups, which are essential for glucose transport (26), have been suggested as possibly being important in the mechanisms of oxidative hemolysis $(14,27)$. It was thought that involvement of these sulfhydryl groups in transport processes might diminish the ability of the red cell to protect itself against damage. However, this possibility also was ruled out by the ineffectiveness of similarly transported but nonmetabolized sugars. Conclusive evidence that the osmotic fragility caused by primaquine was substrate dependent came with the demonstration of protection by inhibition of metabolism. The addition of 2-deoxyglucose, a competitive inhibitor of glucose metabolism (18), partially protected the red cells from primaquine action. Depletion of endogenous substrates by incubation of the red cells at $37^{\circ} \mathrm{C}$ before adding primaquine afforded almost complete protection against the development of osmotic fragility.

Of the various sugars tested, glucose, fructose, mannose, and galactose were all effective in supporting primaquine-induced osmotic fragility. Primaquine action was supported by purine nucleosides as well as metabolized hexoses. The nucleoside effect was localized to the ribose moiety by the finding that adenine alone was ineffective. Also the concentration requirement for adenosine was identical to that of glucose.

A direct relation between metabolism as determined by lactate production and stimulation of primaquine action was obtained using purine nucleosides as substrates. Adenosine and guanosine 
were equal to glucose in supporting primaquine action; deoxyadenosine had only an intermediate effect. Lowy and associates (20) have shown that the same amount of pentose is metabolized (i.e., diminished measurable pentose concentration) by red cells from both adenosine and deoxyadenosine. However, they also showed that lactate production from deoxyadenosine is only onehalf that produced by adenosine. Although lactate is specifically the end product of glycolysis, diminished lactate production by deoxyribose could result from a metabolic deficiency at any point after phosphorylation at the membrane by nucleoside phosphorylase. Therefore, the deoxyadenosinesupported increase in osmotic fragility with primaquine quantitatively correlated with deoxyribose metabolism.

Once a substrate requirement for primaquineinduced membrane damage was established, the character of the reaction had to be determined. Possible energy-requiring steps in primaquine hemolysis are 1) active transport of the drug into and binding by the erythrocytes and 2) metabolic transformation of primaquine to an active compound.

The first possibility was eliminated by determining the uptake and binding of primaquine to red cells under various conditions of incubation. In these experiments, two-thirds of the primaquine was bound to red cells immediately, and no more was taken up during incubation (Table IV). Essentially all of the primaquine could be removed from red cells by washing them once in $20 \mathrm{vol}$ of saline. Neither red cell uptake nor binding of the drug was substrate dependent. Various antimalarial drugs, including primaquine, have been shown by Steinbuch and Quentin (28) to bind directly to red cell stroma in vitro. It was shown that cephalin alone, an acidic lipid compound of red cell membranes, possessed the binding properties of intact red cell stroma. Adsorption and bonding to such surface lipids would be consistent with immediate primaquine uptake and easy removal by washing of the cells.

Molecular structural requirements for oxidative hemolysis and antimalarial action have long been known to be similar $(29,30)$. It is known that 8-aminoquinolines undergo changes in vivo to quinoline quinones, which are more active in vitro as antimalarial and hemolytic agents (3133, Figure 9). The primaquine added to in vitro

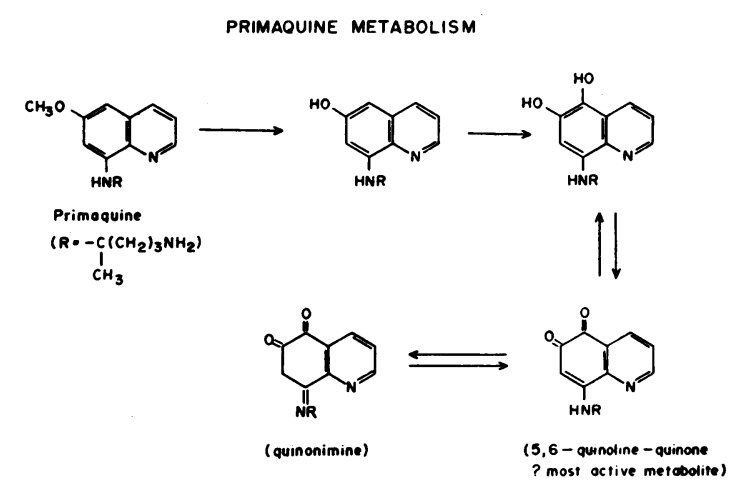

Fig. 9. Primaquine metabolism. This represents the pathway of 6-methoxy-8-aminoquinoline biodegradation suggested by Smith (34) from studies of isotopically labeled pentaquine in monkeys. Figure adapted from Alving, Powell, Brewer, and Arnold (33).

hemolytic systems may not be the hemolytic agent that is active in vivo. Substrate may be required to metabolize primaquine to an active intermediate. This transformation could involve hydrolysis of the 6-methoxy group to a 6-hydroxy group as well as hydroxylation at the 5 position on the quinoline ring (Figure 9). Liver cell microsomes have been shown to metabolize quinoline drugs in this manner in the presence of TPNH and oxygen (35). Whether such transformation can occur in red cells is unknown, but the requirement for the TPNH produced by the pentose phosphate pathway is supported by the present information. Studies with primaquine carried out with G-6-PD deficient red cells showed that substrate was significantly less effective in supporting primaquineinduced osmotic fragility. Since the primary metabolic defect of these cells is a less effective pentose phosphate pathway, the reactions of glucose metabolism supporting primaquine hemolysis are probably in this pathway. Although it has been suggested that galactose is not effectively metabolized through the pentose phosphate pathway (36), in other experiments using galactose $-{ }^{14} \mathrm{C}(37)$ we have confirmed previous work (38) which stated that there is significant ${ }^{14} \mathrm{CO}_{2}$ produced that is stimulated by methylene blue, indicating activity of the pentose shunt. The ${ }^{14} \mathrm{CO}_{2}$ produced was less than that produced with glucose as a substrate, which is consistent with the quantitative difference in the ability to support primaquine action demonstrated in Figure 5. Ribose phosphate from adenosine and guanosine also may not be metabolized 
through the pentose phosphate pathway as much as glucose. Some of the metabolic intermediates from ribose phosphate are recycled through the pentose shunt in the presence of oxidative drugs (21), but others will proceed directly to the formation of lactate. This may be why adenosine is slightly less effective than glucose in stimulating primaquine hemolysis (Figure 5).

Primaquine oxidation is also suggested by the fact that other 8-aminoquinoline drugs, pamaquine and isopentaquine, similarly required substrate for the production of in vitro erythrocyte osmotic fragility. Other oxidative hemolytic drugs tested, acetylphenylhydrazine, hydroquinone, $\beta$-naphthol, and menadione sodium bisulfite, showed no enhancement of their in vitro effect with the addition of glucose. In fact, the depletion of endogenous substrates increased the effect of these drugs.

The paradox of these experiments is that "primaquine sensitive" erythrocytes were actually more resistant than normal red cells to the in vitro action of primaquine in the presence of substrate. However, this in vitro phenomenon must be of little significance in vivo. If TPNH dependent biodegradation is required for primaquine to become active, other cells of the body would completely take over this function.

The discrepancy between concentrations of primaquine required for in vitro hemolysis and the dose that can precipitate hemolytic anemia in sensitive individuals is still unexplained. Perhaps an active metabolite of primaquine has a greater effect on sensitive red cells in vivo in producing membrane damage with diminished surface area, spherocytosis, and subsequent lysis or sequestration.

\section{Summary}

Substrate greatly, enhanced the effect of primaquine on normal red cells in vitro. The presence of substrate produced no change in prelytic potassium loss, a significant but small increase in hemolysis, and a great increase in osmotic fragility. Depletion of endogenous red cell substrates before the addition of primaquine prevented the development of primaquine-induced osmotic fragility.

Red cells incubated with subhemolytic concentrations of primaquine in the presence of substrate became spherocytes without an increase in volume, indicating that there was an effect on the red cell membrane that diminished surface area and decreased critical hemolytic volume.

Glucose 6-phosphate dehydrogenase (G-6-PD) deficient erythrocytes were less susceptible than normal red cells to primaquine-induced osmotic fragility in the presence of substrate. Therefore, the site of the metabolic reaction supporting primaquine action is probably in the pentose phosphate pathway. This pathway may provide electron donors so that primaquine can be metabolized to a more active compound. The reactions involved in the structural transformation of quinoline drugs have been shown in other systems to require TPNH and oxygen. Since G-6-PD deficient red cells are less able to produce TPNH, this may explain their paradoxical resistance to primaquine action in vitro.

\section{Acknowledgment}

We wish to thank Mrs. Sophia Tate for her careful assistance with the preparation of this manuscript.

\section{References}

1. George, J. N., R. L. O'Brien, S. Pollack, and W. H. Crosby. Glucose enhancement of red cell membrane damage by primaquine. Clin. Res. 1965, 13, 273.

2. Clayman, C. B., J. Arnold, R. S. Hockwald, E. H. Yount, Jr., J. H. Edgcomb, and A. S. Alving. Status of primaquine. 3. Toxicity of primaquine in Caucasians. J. Amer. med. Ass. 1952, 149, 1563.

3. Hockwald, R. S., J. Arnold, C. B. Clayman, and A. S. Alving. Status of primaquine. 4. Toxicity of primaquine in Negroes. J. Amer. med. Ass. 1952, 149, 1568.

4. Jacob, H. S., S. H. Ingbar, and J. H. Jandl. Oxidative hemolysis and erythrocyte metabolism in hereditary acatalasia. J. clin. Invest. 1965, 44, 1187.

5. Tarlov, A. R., G. J. Brewer, P. E. Carson, and A. S. Alving. Primaquine sensitivity. Arch. intern. Med. 1962, 109, 137.

6. Beutler, E., R. J. Dern, and A. S. Alving. The hemolytic effect of primaquine. III. A study of primaquine-sensitive erythrocytes. J. Lab. clin. Med. 1954, 44, 177.

7. Beutler, E. R. Drug-induced hemolytic anemia (primaquine sensitivity) in The Metabolic Basis of Inherited Disease, 2nd ed., J. B. Stanbury, J. B. Wyngaarden, and D. S. Fredrickson, Eds. New York, McGraw-Hill, 1966, p. 1060.

8. Harley, J. D., and A. M. Mauer. Studies on the formation of Heinz bodies. I. Methemoglobin 
production and oxyhemoglobin destruction. Blood 1960, 16, 1722.

9. Mohler, D. N., and C. L. Crockett, Jr. Hereditary hemolytic disease secondary to glucose-6-phosphate dehydrogenase deficiency: report of three cases with special emphasis on ATP metabolism. Blood $1964,23,427$.

10. Miller, A., and M. Horiuchi. Erythrocyte glutathione. II. The effect of acetylphenylhydrazine and primaquine on the entry and incorporation of $\mathrm{C}^{14}$ glycine in glutathione. J. Lab. clin. Med. 1965, 66, 84.

11. Florkin, M., and E. H. Stotz, Eds. Comprehensive Biochemistry. Report of the Commission on Enzymes of the International Union of Biochemistry, revised ed. Amsterdam, Elsevier, 1964, vol. 13, p. 5.

12. Crosby, W. H., J. I. Munn, and F. W. Furth Standardizing a method for clinical hemoglobinometry. U. S. armed Forces med. J. 1954, 5, 693.

13. Parpart, A. K., P. B. Lorenz, E. R. Parpart, J. R. Gregg, and A. M. Chase. The osmotic resistance (fragility) of human red cells. J. clin. Invest. 1947, 26, 636.

14. Weed, R., J. Eber, and A. Rothstein. Effects of primaquine and other related compounds on the red blood cell membrane. I. $\mathrm{Na}^{+}$and $\mathrm{K}^{+}$permeability in normal human cells. J. clin. Invest. 1961, 40, 130.

15. LeFevre, P. G. Sugar transport in the red blood cell: structure-activity relationships in substrates and antagonists. Pharmacol. Rev. 1961, 13, 39.

16. Bishop, C. Overall red cell metabolism in The Red Blood Cell, C. Bishop and D. M. Surgenor, Eds. New York, Academic Press, 1964, p. 161.

17. Wool, I. G. Incorporation of $\mathrm{C}^{14}$ from $\mathrm{C}^{\mathbf{1 4}}$-labeled sugars into $\mathrm{CO}_{2}$, nucleic acids and protein by isolated rat diaphragm. Amer. J. Physiol. 1960, 198, 649.

18. Wick, A. N., D. R. Drury, H. I. Nakada, and J. B. Wolfe. Localization of the primary metabolic block produced by 2-deoxyglucose. J. biol. Chem. 1957, 224, 963.

19. Huennekens, F. M., E. Nurk, and B. W. Gabrio. Erythrocyte metabolism. I. Purine nucleoside phosphorylase. J. biol. Chem. 1956, 221, 971.

20. Lowy, B. A., E. R. Jaffé, G. A. Vanderhoff, L. Crook, and I. M. London. The metabolism of purine nucleosides by the human erythrocyte in vitro. $\mathrm{J}$. biol. Chem. 1958, 230, 409.

21. Szeinberg, A., and P. A. Marks. Substances stimulating glucose catabolism by the oxidative reactions of the pentose phosphate pathway in human erythrocytes. J. clin. Invest. 1961, 40, 914.

22. Kosower, N. S., G. A. Vanderhoff, E. R. Jaffé, and I. M. London. Metabolic changes in normal and glucose-6-phosphate dehydrogenase-deficient erythrocytes induced by acetylphenylhydrazine. J. clin. Invest. 1963, 42, 1025.

23. Weed, R. I. Effects of primaquine on the red blood cell membrane. II. $\mathrm{K}^{+}$permeability in glucose-6phosphate dehydrogenase deficient erythrosytes. J. clin. Invest. 1961, 40, 140.

24. Harley, J. D., and A. M. Mauer. Studies on the formation of Heinz bodies. II. The nature and significance of Heinz bodies. Blood 1961, 17, 418.

25. Crosby, W. H. The pathogenesis of spherocytes and leptocytes (target cells). Blood 1952, 7, 261.

26. Vansteveninck, J., R. I. Weed, and A. Rothstein. Localization of erythrocyte membrane sulfhydryl groups essential for glucose transport. J. gen. Physiol. 1965, 48, 617.

27. Jacob, H. S., and J. H. Jandl. Effects of sulfhydryl inhibition on red blood cells. I. Mechanism of hemolysis. J. clin. Invest. 1962, 41, 779.

28. Steinbuch, M., and M. Quentin. A propos de l'affinité de quelques antipaludiques pour le globule rouge. Arch. int. Pharmacodyn. 1957, 110, 10.

29. Emerson, C. P., T. H. Ham, and W. B. Castle. Hemolytic action of certain organic oxidants derived from sulfanilamide, phenylhydrazine, and hydroquinone (abstract). J. clin. Invest. 1941, 20, 451.

30. Schönhöfer, F. Uber die Bedeutung der chinoiden Bindung in Chinolinverbindungen für die Malariawirkung. Hoppe-Seylers Z. physiol. Chem. 1942, $274,1$.

31. Josephson, E. S., D. J. Taylor, J. Greenberg, and A. P. Ray. A metabolic intermediate of pamaquine from chickens. Proc. Soc. exp. Biol. (N. Y.) 1951, 76, 700 .

32. Josephson, E. S., J. Greenberg, D. J. Taylor, and H. L. Bami. A metabolite of pamaquine from chickens. J. Pharmacol. exp. Ther. 1951, 103, 7.

33. Alving, A. S., R. D. Powell, G. J. Brewer, and J. D. Arnold. Malaria, 8-aminoquinolines, and haemolysis in Drugs, Parasites, and Hosts, L. G. Goodwin and R. H. Nimmo-Smith, Eds. London, J. \& A. Churchill, 1962, p. 83.

34. Smith, C. C. Metabolism of pentaquine in the rhesus monkey. J. Pharmacol. exp. Ther. 1956, 116, 67.

35. Fishman, W. H. Chemistry of Drug Metabolism. Springfield, I1l., Charles C Thomas, 1961, pp. 28, 65.

36. Beutler, E., and Z: Collins. Methaemoglobin reduction: studies using galactose as substrate. Scand. J. Haemat. 1965, 2, 343.

37. George, J. N., and R. L. O'Brien. Unpublished observation.

38. Isselbacher, K. J. Galactosemia in The Metabolic Basis of Inherited Disease, 2nd ed., J. B. Stanbury, J. B. Wyngaarden, and D. S. Fredrickson, Eds. New York, McGraw-Hill, 1966, p. 178. 